\title{
The methodology of estimation of transport demand by the parameters of location of the mass gravitation centers in the urbanized territories
}

\author{
Anton Zedgenizov ${ }^{1, *}$ \\ ${ }^{1}$ Irkutsk National Research Technical University, 664074, Lermontova str., 83, Irkutsk, Russia
}

\begin{abstract}
The methodology of estimating transport demand by the parameters of location of the mass gravitation centers in the urbanized territories is considered in the article. The basis of the methodology is a basic scheme, conditionally divided into 4 main blocks and 17 steps. The first block is aimed at collecting primary information about the center of mass gravitation under consideration, the second one is for assessing transport demand during the daily period, the third one is necessary for assessing the quality of transport services for visitors of the considered center of mass gravity, for example, the calculation of the required number of parking slots or throughput, and confusing intersections. The fourth block is necessary for estimating the transport capacity of the calculation areas, and is the source of the initial data for transport planning at the second stage (trip distribution). It is also proposed to assess the accuracy of the proposed methodology on the basis of comparing the calculated values of the intensity of transport streams on the city's network with the actual ones. On average, the deviation was $11 \%$, which seems to be an acceptable accuracy for enlarged transport calculations.
\end{abstract}

\section{Introduction}

In accordance with the generally accepted approach to transport planning based on the fourstep model, the first two steps refer to the estimation of the transport demand: the estimation of the generating capacity of the mass gravitation centers (MGC) (identification of the capacity on arrival and departure) and the assessment of transport demand at the pre-network level (calculation of inter-district correspondence matrix). Before the calculation of the capacity of the transport settlement areas (TSA) is started, it is necessary to create corresponding databases containing information on the number of TSAs, their relative location on the city plan (district plan), the distance from the city center, the areas of MGC of different functional orientation, etc. 


\section{Materials and methods}

At the first step of the methodology, the general functional diagram of which is presented on the Figure 1, it is necessary to determine the spatial characteristics considered by MGC. The area of TSA is currently easy to determine with the help of modern geo-information systems (2GIS, Google Earth, etc.). It is important to make some explanations regarding the boundaries of the territory to be measured. Depending on the typology of MGC, the process of measuring the area will be different. It is important to understand which territory should be considered in its entirety with all the buildings, structures, auxiliary premises, and in which only the buildings are to be taken, and such a territory will be considered as a separate MGC. As a rule, it is difficult to single out industrial areas into separate buildings, since the main workshops, auxiliary rooms and production areas in the open air are involved in the production process, so in this case it is necessary to consider the entire area without taking into account the number of floors. The low-rise buildings (private sector), gardening noncommercial partnerships (GNCP), recreation and entertainment parks, markets and other similar territories united by a single production or other activity should be included in the same territories. Such territories, as a rule, are limited with artificial fences or natural obstacles, such as rivers, ravines, etc.

On the other hand, there are MGCs, which can largely change in their areas due to the increase in the number of floors: multi-floor residential buildings, shops, large shopping and entertainment centers, theaters, cinemas, and other mass gravitation centers concentrated, as a rule, in one building. In these cases when measuring the area, the floors are taken into account. So, for example, with the measuring the area of the detached buildings, one should take into account the floor area, which is determined by the external dimensions of the building. Technical floors, attics, etc. are not involved into the calculation.

\section{Research}

The second step reveals the activity of the territory on weekdays and weekends, as well as on the seasons of the year. At the same time, the typology of MGC should be taken into account. For example, the activity of residential areas on weekdays is reduced, but of the objects of cultural and household orientation is growing (with the exception of sports and fitness complexes). The goal that is pursued in assessing transport demand should also be taken into account. If it is a question of improving the quality of transport services for a local MGC, then the most active period is chosen. In the case of assessing transport demand at the macro-level, it is necessary to use data for a weekday without seasonal fluctuations.

The third step reveals the availability of reference data on the basic quantitative characteristics of the MGC functioning. They are taken from the respective directories and used in calculations. At the fourth step, a full-scale field study is possible to identify these characteristics.

The estimation of the daily amount of visitors $E$ is realized at the fifth step and is reduced to the use of initial data in the form of quantitative characteristics, for example, in the production of the specific generation of correspondence $G$ by area $S$ of the MGC under consideration, or using a regression equation in which the number of visitors is considered, taking into account additional factors, first of all, spatial characteristics (remoteness from the city center, main street, etc.). For example, the amount of visitors to supermarkets will be affected by the distance from the city center, and the further is the supermarket from the city center, the higher is the number of visitors. 


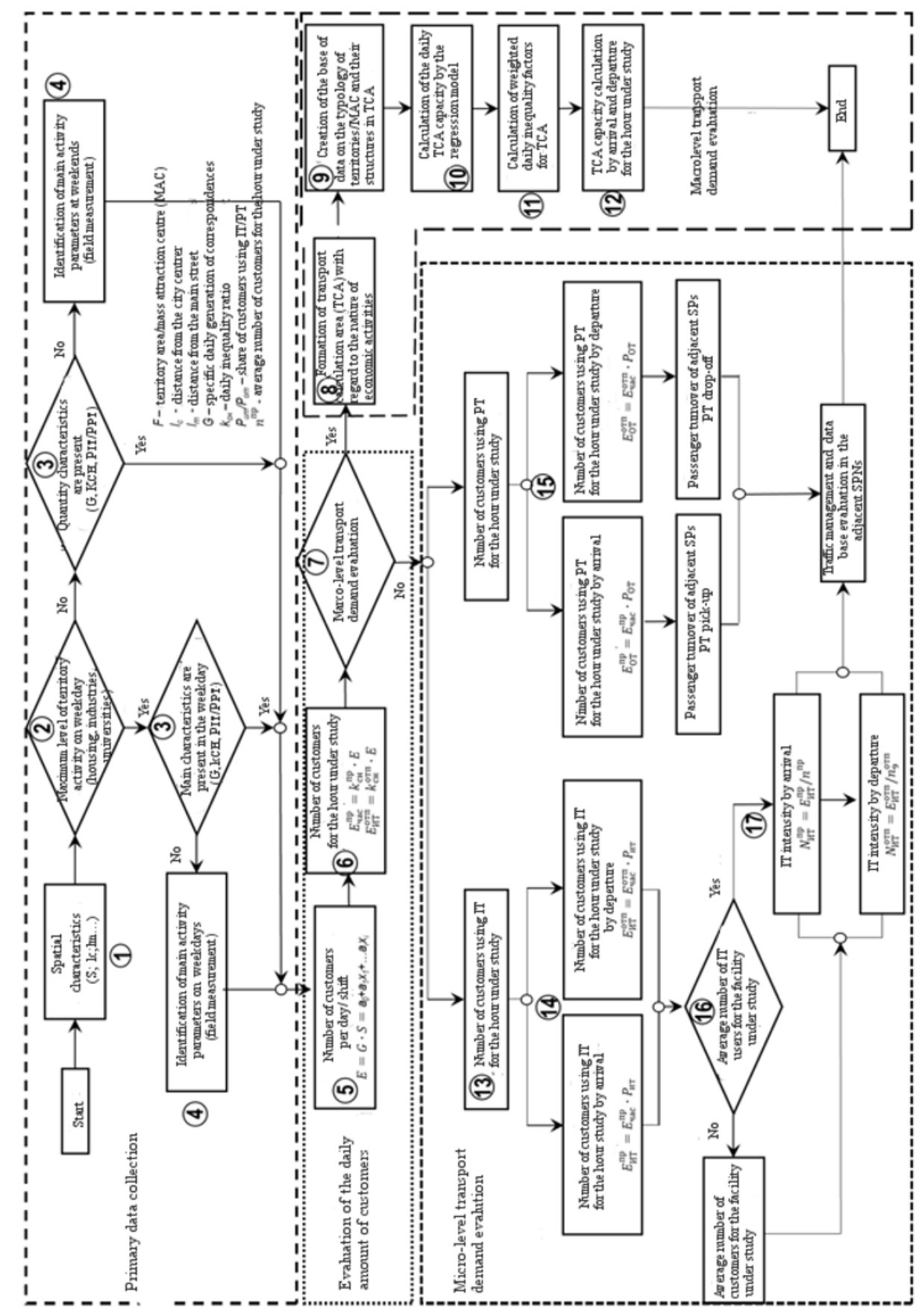

Fig. 1. Schematic diagram of the transport demand assessment by the parameters of the MGC location in the urbanized territories.

For practical calculations and forecasting peak periods, information on the number of visitors per hour is required $E_{\text {uac. }}$. Such information can be obtained at the sixth step on the basis of the daily non-uniformity (on arrival and departure) coefficients, reflecting the share of MGC load during the day (or the shift). 
The assessment of transport demand at the macro-level, the seventh step, implies the calculation of the capacity of the TSAs, upon arrival and departure, on the basis of the initial data for each of the TSA. To solve this difficult task, at the eighth step it is necessary to form TSAs that meet the general requirements.

The formation of a database on the typology of MGC occurs at the ninth step, which is necessary to calculate the capacity of the TSA, and the mathematical analysis of the spatial and quantitative characteristics of each of the TSAs. In fact, the researcher receives aggregate information on TSA, consisting of hundreds, and in some cases, thousands of MGCs located in the TSA under consideration. Often these territories are divided not only relative to physical structures, but also within the same building.

The calculation of the TSA capacity is carried out at the tenth step on the basis of data on the structure of the MGC types and their area as referred to TSAs. The eleventh step is devoted to the calculation of the weighted average daily non-uniformity coefficients. Since TSA is a conglomerate of MGCs, it is necessary to calculate the weighted average daily nonuniformity (on arrival and departure) for each TSA:

$$
k_{\mathrm{cm}}=k_{100} \cdot D_{100}+k_{202} \cdot D_{202} \cdots+\cdots k_{n} \cdot D_{n},
$$

where: $k_{100}$ is the daily maximum coefficient corresponding to the type of territory application; $D_{100}$ - the share of the type of territory. The calculation of the TSA capacity at the calculated hour, step twelve, can be used in further calculations in the following stages of trip distribution.

The twelfth step considers the procedure for calculating the TSA capacity on arrival and departure for the hour in question. In fact, this is the initial data for the second stage of transport planning. The estimation of the transport demand at the micro-level begins from the thirteenth step of the proposed methodology and is more sensitive to errors than in the macro-level. The errors arising in the calculation may indicate a shortage of capacity, adjacent road network or parking spaces. In this step it is necessary, using the data on the number of visitors for the hour in question, on the arrival of $E_{\text {час }}^{\text {пр }}$ or the departure $E_{\text {час }}^{\text {отп }}$, to calculate the number of visitors for this hour on individual transport (IT) (the fourteenth step) and the share of visitors without using IT (the fifteenth step) together with foot correspondences. To do this, one uses the share of visitors arriving on IT and without it. As a rule, the share of visitors on IT on arrival and departure is about the same. The data obtained at the fifteenth step ( $E_{\text {Без ит }}^{\text {пр }}$ and $E_{\text {Без ит }}^{\text {отп }}$ ) can be used in forecasting passenger traffic on the public transportation (OT), calculating the passenger turnover of stopping points or designing pedestrian communications.

At the sixteenth step, one needs selecting the average IT content. Based on the number of visitors per hour by IT, both on the arrival of $E_{\text {ИT }}^{\text {пр }}$, and on the departure of $E_{\mathrm{UT}}^{\text {отп }}$, it is necessary to calculate the IT intensity upon arrival of $N_{\text {ИT }}^{\text {חp }}$ and the departure of $N_{\text {ИT }}^{\text {oTn }}$ (step seventeen). The calculation is to be made on arrival and departure. As a result of the assessment of transport demand at the micro-level, it is possible to assess the degree of influence of MGC on the adjacent road network.

As an example, the calculation of the number of visitors to the local MGC can be done on the basis of a housing estate located in one of the micro-districts of Irkutsk. To calculate the daily amount of visitors, the data of territorial location (area, specific generation of correspondence and distance from the city center) are required. The calculation is carried out according to the regression equation 4.8 :

$$
\mathrm{E}=0.018 \cdot 7228+0.18 \cdot 4500-590=345 \text { people } / \text { day }
$$


In the absence of the regression equation, one can use the average value of the specific generation of correspondences, which for this type of territory is 0.042 people $/ \mathrm{m}^{2}$. Thus, $\mathrm{E}$ $=0.042 \cdot 7228=303$ people $/ \mathrm{m}^{2}$. The calculated values differ insignificantly, by $13 \%$, since a typical MGC was chosen for the example, located at a slight distance from the city center. It is interesting to note that when comparing objects located on the periphery of the city, the similarity of the calculated results will be less $(34 \%)$ :

$$
\begin{gathered}
\mathrm{E}=0.018 \cdot 89961+0.18 \cdot 12196-590=3200 \text { people } / \text { day } \\
\mathrm{E}=0.048 \cdot 89961=4318 \text { people } / \mathrm{M}^{2}
\end{gathered}
$$

Such an error arises from the influence of the factor of distance from the city center, so the regression equations are preferable than the average value of the specific generation of correspondences.

When estimating the number of visitors (TSA capacity) for the daily period (the tenth step of the methodology), it is necessary to take into account the total correspondences that gravitates towards the MTC located inside the TSA. Obviously, not all MGCs located in the TSA should be considered, since many of them are centers of gravitation that function directly inside the TSA, and therefore they do not need to be accounted for the daily amount of visitors (schools, kindergartens, post offices, convenience stores, consumer services, etc.). Along with this, the daily amount of visitors gives only a comparative assessment of the generating capacity, and serves as an intermediate stage for calculating the number of visitors at the settlement hour, usually a peak one.

To calculate the inter-district correspondence matrix, only the data of the TSA capacity on arrival and departure for the hour in question is not sufficient. The calculation of the matrix of inter-district correspondences, in accordance with the gravitational model, requires the availability of data on the positioning of the TSA or data on the degree of difficulty of communication between these TSAs.

\section{Results and discussion}

Verification of the received inter-district correspondence matrix according to the proposed methodology is necessary to confirm its operability, as well as to identify its points, which introduce the greatest error in the calculations. The basis for the verification of the methodology is the matrix of inter-district correspondence, which allows calculating the intensity of traffic flows on the road network. In view of the absence of tasks aimed at realizing the full cycle of the four-stage transport planning model in this study, the author will limit himself to calculating / measuring the intensity at the periphery of the city, in the formation of which only certain TSAs will participate without alternative modes of movement (Figure 2).

To determine the intensity of the traffic flow generated by the Novo-Lenino micro-district (TSA 58-64, 90), it is necessary to carry out vehicle intensity measurements at the peak hours (from 8:00 to 9:00) in several sections, which allow excluding transit traffic from the federal highway M-53, as well as take into account both main streets that feed this neighborhood (bypass road Novo-Lenino and Rosa Luxemburg street). The scheme of measurement and the results of the measured intensity are shown in the Figure 3.

Thus, the total volume of the traffic flows intensity generated by the Novo-Lenino microdistrict can be defined as the sum of the intensity in section 2, and the sum of the intensity in section 3 minus the transit flow measured at section 1: $(3544+1784-2096=3232$ auto / hour). The measurements of the intensity of the traffic flow generated by the Irkutsk 2 micro- 
district are presented at section 4 (1324 auto / hour). The measured intensity measurements for the selected key sections are summarized in the Table 1.

The calculation of intensity in the sections under consideration is reduced to the summation of all correspondences on departure from the considered micro-district (TSA aggregate) to other TSAs. From the point of view of the matrix of inter-district correspondences, this is the sum of all correspondences per column (s) corresponding to the TSA. Thus, the total volume of correspondences must be converted into the intensity of the traffic flow, taking into account the distribution of the share of travels on individual transport and its average indicator. It is important to note, that for each TSA, there are own weighted average values. Further calculations are performed in accordance with the procedure as on the Figure 1, steps 13-17 [10]. The results of the calculations are summarized in the Table 1.

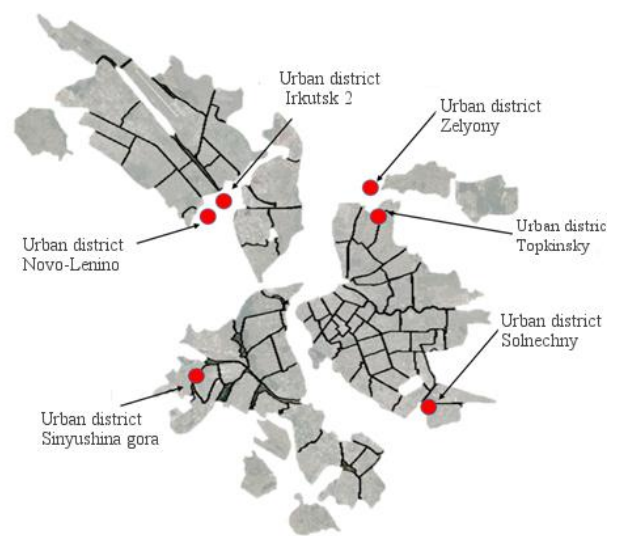

Fig. 2. Places of the control measurements of the intensity of traffic flows.

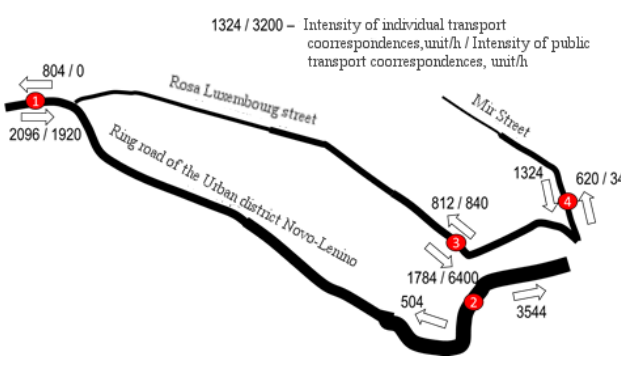

Fig. 3. Places of the control measurements of the intensity of traffic flows in the NovoLenino and Irkutsk 2 micro-districts.

Table 1. Results of verification of the calculated and actual traffic flow intensity.

\begin{tabular}{|l|c|c|c|c|c|c|}
\hline & \multirow{2}{*}{$\begin{array}{l}\text { Name of } \\
\text { the district }\end{array}$} & $\begin{array}{c}\text { Volume of } \\
\text { correspondenc } \\
\text { es }\end{array}$ & $\begin{array}{c}\text { Share of } \\
\text { individua } \\
\text { transport }\end{array}$ & Average & & \multicolumn{2}{|c|}{$\begin{array}{c}\text { Intensity, on } \\
\text { content }\end{array}$} & \multirow{2}{*}{$\begin{array}{l}\text { Estimate } \\
\mathrm{d}\end{array}$} & $\begin{array}{l}\text { Mepasure } \\
\mathrm{d}\end{array}$ & $\begin{array}{c}\text { Deviatio } \\
\mathrm{n}, \%\end{array}$ \\
\hline $\begin{array}{l}\text { Novo- } \\
\text { Lenino }\end{array}$ & 10428 & 0,45 & 1,58 & 2971 & 3232 & 8 \\
\hline Irkutsk 2 & 2740 & 0,57 & 1,49 & 1054 & 1324 & 20 \\
\hline Zelenyi & 918 & 0,78 & 1,52 & 471 & 408 & -16 \\
\hline $\begin{array}{l}\text { Solnechny } \\
\text { i }\end{array}$ & 3197 & 0,43 & 1,50 & 914 & 1100 & 17 \\
\hline $\begin{array}{l}\text { Sinyushin } \\
\text { a Gora }+ \\
\text { Lugovoie }\end{array}$ & 3512 & 0,43 & 1,50 & 1007 & 1101 & 9 \\
\hline Topkinsky & 851 & 0,75 & 1,50 & 426 & 398 & -7 \\
\hline
\end{tabular}

It can be seen from the graph and the table that the discrepancies are not significant. On average, the relative deviation is $11 \%$, which meets the accuracy requirements for the enlarged transport computations. 


\section{References}

1. R. Vučik, Transport in cities convenient for living (Territory of the Future, Moscow, 2011)

2. V. V. Sheshtokas, V. I. Adomavičius, P. V. Yushkevičius, Garages and parking lots (Stroyizdat, Moscow, 1984)

3. G. A. Golts, Transport and resettlement (Nauka, Moscow, 1981)

4. I. S. Efremov, V. M. Kobozev, V. A. Yudin, The theory of urban passenger transportation (Higher School of Economics, Moscow, 1980)

5. A. V. Zedgenizov, D. G. Burkov, Collected papers of the twelfth International scientific-practical conference in SPbGASU, 235-242 (2016)

6. A. V. Zedgenizov, Proceedings of the Irkutsk State Technical University, 4(111), 187 192 (2016)

7. R. Kitamura, Transportation Research Board Special Report, 220 (1988)

8. W. A. Martin, N. A. McGuskin. National Cooperative Research Program Report, 365 (1998)

9. Institute of Transportation Engineers, Trip generation (Washington, DC, 2008)

10. A. V. Bogoviz, S. V. Lobova, A. N. Alekseev, I. A. Koryagina, T. V. Aleksashina, Advances in Intelligent Systems and Computing, 622, 609-616 (2018) 